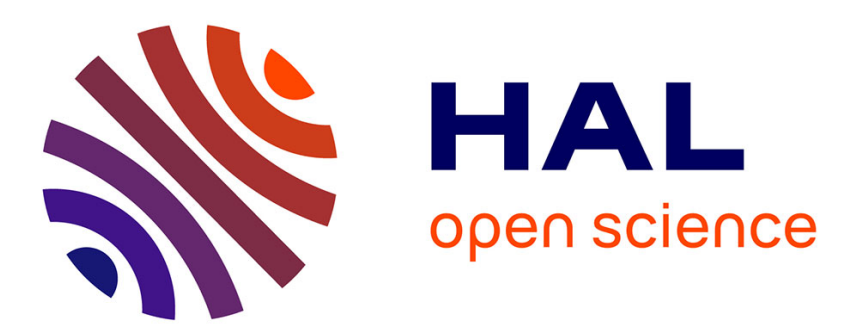

\title{
An ecological framing of HIV preventive intervention: a case study of non-government organizational work in the developing world
}

\author{
Annabelle Mooney, Srikant Sarangi
}

\section{- To cite this version:}

Annabelle Mooney, Srikant Sarangi. An ecological framing of HIV preventive intervention: a case study of non-government organizational work in the developing world. Health, 2005, 9 (3), pp.275296. 10.1177/1363459305052901 . hal-00571412

\section{HAL Id: hal-00571412 \\ https://hal.science/hal-00571412}

Submitted on 1 Mar 2011

HAL is a multi-disciplinary open access archive for the deposit and dissemination of scientific research documents, whether they are published or not. The documents may come from teaching and research institutions in France or abroad, or from public or private research centers.
L'archive ouverte pluridisciplinaire HAL, est destinée au dépôt et à la diffusion de documents scientifiques de niveau recherche, publiés ou non, émanant des établissements d'enseignement et de recherche français ou étrangers, des laboratoires publics ou privés. 


\title{
An ecological framing of HIV preventive intervention: a case study of non-government organizational work in the developing world
} DOI: $10.1177 / 1363459305052901$ 1363-4593; Vol 9(3): 275-296

\author{
Annabelle Mooney \& Srikant Sarangi \\ Cardiff University, $U K$
}

ABSTRACT The work that non-governmental organizations (NGOs) perform in terms of HIV and AIDS is wide-ranging. Financial resources are available from government and other agencies if NGOs can frame their work in alignment with their interests. We take the particular case of Disha Foundation, an NGO working in Nasik, in the state of Maharashtra in India, whose clients are migrant workers. Drawing upon a broad notion of frame, we focus on the way in which activities such as 'intervention', 'prevention', 'empowerment' and 'community' in the HIV field can differ radically from articulation (at a government level) to practice (of NGOs). Disha's interventions can be described as ecological, in so far as they map and change root causes. Thus, Disha can be seen as doing HIV prevention. Further, we argue that framing HIV funding calls primarily in terms of 'quality of life' would facilitate the work of NGOs, especially of ecological interventions.

KEYWORDS ecological interventions; framing; HIV; India; migrants; NGOs

AdDress Annabelle Mooney, Health Communications Research Centre, Cardiff University, Humanities Building, Coulm Drive, Cardiff, CF10 3EV, UK. [Tel: +44 (0)29 2087 4243; fax: +44 (0)29 2087 4343; e-mail: mooneya@ cf.ac.uk]

ACKnowledgements Thanks to ActionAid UK and Bangalore and to Disha and the client groups it works with. The 'Language and Global Communication' research programme of the Centre for Language and Communication Research has been funded for a five-year period by the Leverhulme Trust. We would also like to thank the very helpful comments of anonymous referees. 


\section{Introduction: NGOs in the field of HIVIAIDS in developing countries}

The active involvement of non-governmental organizations (NGOs) in the management of HIV/AIDS world-wide can be seen as part of globalization in terms of a general turn to neo-liberal politics and economics. Their primary role is one of mediating between communities and government agencies as well as external donors, to whom they are not only accountable but also often dependent upon for survival. It is worth noting that NGOs have come into existence via governments partly because of the reluctance on the part of mainstream government agencies to undertake certain programmes, as is the case with HIV/AIDS prevention.

NGOs are usually seen as doing 'good', but also doing things that governments are unable to do or do not want to do themselves. This puts NGOs in a surrogate role as the government concerned sets procedures and defines situations for intervention. Principles of accountability and pressure for professionalization abound (Edwards and Hulme, 1995). In a sense, most NGOs are caught between 'doing right' (by the government) and 'doing good' (by communities). This is no different in developing countries. Altman notes (following Thorpe), that 'governments have fostered community organizations as an alternative to more costly direct interventions, while at the same time such organizations develop from the anger of those who find the existing state is unable to meet their demands' (1997). It is important to remember that the anger impetus does not recede with the development of community organizations, and in many cases increases because of the pressures and challenges of working with governments. While governments and donor agencies work in a variety of ways, it can be argued that some sponsors treat NGOs as cheap and effective subcontractors.

While it is not the purpose of this article to detail the differences between HIV prevention in developing countries and those arguably better suited to dealing with the epidemic, a few observations should be made. Among other reasons, the lack of health infrastructure and basic facilities (water and sanitation), lack of economic development in certain sectors and challenges due to cultural traditions and isolated communities mean that successful HIV intervention in developing countries often has to be very inventive. While governments in the West are largely content with broad information campaigns supported by medical testing, treatment and support, such technologies are not always available or appropriate in developing areas (though projects like this do take place). ${ }^{1}$ This is not to say that NGOs in the West are unimportant. In many ways, they can be seen as driving and sustaining government action.

Problems in developing countries can be as 'simple' as lacking appropriate vocabulary for and understanding of reproductive health processes (Cornwall, 2002) or not conforming to western models of individuality and sexuality (Jenkins, 1993; Karnik, 2001). Chronic existing health problems 
(often due to lack of basic infrastructure) lower resistance to illness and make treating conditions more challenging (Barnett and Whiteside, 2002: 15). Poverty leading to sex work as a means of survival is another facet of the problem. Sex work is even more problematic when means of prevention (such as condoms) are unavailable or culturally unacceptable (Altman, 2001: 71; Vasudev, 2002). ${ }^{2}$ The particular situation of women is arguably even worse with respect to all these issues. In places such as India where women are often second-class citizens, their existing vulnerability is exacerbated by the impossibility of negotiating safe sex (Potterat, 1993; Pais, 1996; Sen, 2000: 115 ff.; Ananthaswamy, 2003).

As HIV is a declared priority for many governments, NGOs can avail themselves of funds if they frame their work in accepted ways. Thus, one notices a tendency on the part of NGOs to speak the language of government. This kind of alignment manifests as matches with themes and issues, which is why many NGOs declare an explicit interest in certain causes (e.g. HIV), in line with government agendas. While this makes good pragmatic sense, it may not always be possible (or desirable) to frame necessary interventions in these ways. In this article, we pursue a close analysis of government-generated materials, which underlie the process of HIV funding for NGOs in India. The presuppositions in these materials are at odds with current literature in the field of HIV interventions. They are also at odds with the approach that our case study NGO takes to its interventions, which, while not explicitly directed towards HIV, nevertheless prevent the conditions that lead to 'risk behaviour'. Because their interventions target root causes, we identify them as 'ecological' interventions. By this we mean that programmes and interventions are designed and carried out with concern for the relationships that people have to each other and to their social, economic and cultural context. Thus ecological interventions take account of issues such as gender empowerment, economic status, language issues and cultural positioning (whether a group is a stigmatized one, for example). They also work towards solutions that are possible with existing resources. We do not use ecological in Beck's sense of a global, interconnected environment and society (1992: 39). Rather, the environment (natural and social) that we are concerned with is that which immediately impinges on the client group at hand. We retain the concept of interconnectedness, yet focus more on the local and immediate than the global.

We contend that the framing of interventions discursively is of great importance. Because of the power of government agencies and NGOs' accountability, the way government requires interventions to be framed influences in direct and detailed ways the work that many NGOs conduct. We suggest that it may be possible for NGOs to frame funding proposals and programmes in terms of 'quality of life' as this would mean that their field expertise would be both apparent and utilized. This certainly seems possible in the instance of our case study NGO.

The rest of the article is divided into four sections. First, in section 2, we 
offer a brief outline of our research site, methodologies and analytic framework. In section 3, we elaborate the concept of 'targeted interventions' in the context of government HIV/AIDS policies and practice in India. We then show how these concepts are inappropriate to Disha's work. In section 4 , we propose an alternative way of conceiving of Disha's work, which addresses problems in an ecological manner. In such initiatives, while HIV is not foregrounded (or even raised as such), the conditions for vulnerability are none the less removed. Finally, in section 5, we examine the advantages of such reframing. In particular, we argue that the ecological interventions to be described can be accounted for as framing development in terms of 'quality of life'. Such framing aligns with ecological perspectives as well as being politically expedient.

\section{Research site and analytic framework}

\section{Research site and method: Disha Foundation}

Disha was formed by Ms Anajli Borhade in direct response to what she perceived as the needs of migrant workers in Nasik. Disha works particularly with tribal migrants from the tribal belt around Nasik. Programmes focus both on improving the conditions of urban migration and of the villages themselves. Borhade had been working in a local HIV NGO providing exactly the kind of targeted interventions that NACO (National Aids Control Organization of India) encourages. She says, 'I started Disha because I was working with HIV and the issues of reproductive health and I felt that there are some other issues which are [more] ... important than all these issues [to the migrant communities]' (ll. 6-8). ${ }^{3}$

While HIV was (in this incidental way) the starting point for the founding of Disha, HIV is not a perceived priority for migrant workers even though NACO have identified them as a risk group. We will come back to the reasons for this. Indeed, HIV was only ever mentioned by Borhade when specifically asked about it. Documentation of programmes and applications for funding which Disha has made available do not frame interventions in terms of HIV, though it is mentioned in project descriptions for sexual health initiatives. Far more salient, and pressing for migrants, are issues of work, shelter and economic security. When speaking to the migrants that Disha works with, no-one mentioned HIV. Very generally, the women spoke about access to health care and improved living conditions (sanitation, shelter and water), and the men commented on support in employment issues.

As we shall see, the profile of programmes routinely funded by the Indian government differs markedly from the framing of Disha initiatives. The question of what counts formally as 'intervention' and 'prevention' is an important one for the continued existence of NGOs. It is also an important one for managing HIV. Disha is not an HIV NGO as such. While many NGOs in India and the rest of the world work exclusively or at least with 
programmes exclusive to HIV awareness, prevention and care, Disha does not. Nor does Disha receive government money. While the organization has close links with government, especially at the local and regional level, this usually involves procuring assistance for client groups through existing avenues (such as pensions, water access, education and health) or assistance in accessing groups for interventions (most notably for prison populations).

Initial contact with Disha Foundation was facilitated through a training programme (in which one of the authors attended primarily as participant, but also as researcher $)^{4}$ around HIV prevention in Bangalore early in 2003, which dealt with Stepping Stones. ${ }^{5}$ While Disha is not prima facie an HIV NGO, it took part in this training and has consistently employed the participatory methodologies that underpin the package. Indeed, Stepping Stones is itself an excellent example of ecological intervention (Welbourn, 1995). In terms of our own cultural perspectives, neither of the authors live in India.

One of the authors subsequently visited Nasik in April 2003 and again in November 2004. The approach taken in this case study is broadly ethnographic. Apart from two formal interviews (one for each period) and organization documentation, observation, field notes and informal interaction with client groups and other stakeholders (government representatives and medical professionals) was also undertaken. Each visit lasted two weeks and was spent with Ms Borhade at her office and home, at programme sites and attending meetings with government, local authorities and individual clients. The villages from which migrants come, as well as the places in Nasik city where they stay (nagas), were visited on several occasions as part of ongoing programme work. Thus details about projects that Disha facilitates were gathered from site visits, speaking with migrants and other stakeholders.

\section{Analytic framework and risk}

For our analytic framework, we have chosen the broad notion of frame to interpret how different activities are conducted and accounted for in situated ways. This approach is clearest in the following sections dealing with government discourse, in particular, documents produced by NACO. However, a broad concept of frame has also determined how we conceive of Disha's work within existing paradigms of development work and HIV programmes. We will come back to this second broad application presently. Finally, we also employ the concept of frame to suggest that Disha's work can be understood in terms of 'quality of life'.

Fillmore draws our attention to the power of words to influence our thought and action: 'words represent categories of experience, and each of these categories is underlain by a motivating situation occurring against a background of knowledge and experience' (1982: 111-12). Although Fillmore's work is limited to sentence-level linguistic realizations, it has the 
potential for extension to the discourse level to interpret how human action is framed in terms of agency, responsibility and intervention. For instance, in any linguistic performance, intertextuality is at work that acknowledges the existence of specific contexts vis-a-vis the histories of words. The use of one concept or word in a frame makes available all other concepts from the same frame.

The combined notion of intertextuality and frame has been developed further by Fairclough in relation to representations of voices in a text in the political sphere: 'when the voice of another is incorporated into a text, there are always choices about how to "frame" it, how to contextualise it, in terms of other parts of the text' (2003:53). Goffman (1974) claims, following Bateson, that 'frame' is a social element of the communication system. In interpersonal, interactional settings, it consists of 'principles of organisation which govern events - at least social ones - and our subjective involvement in them' (Goffman, 1974: 10). Unlike Fillmore, Goffman focuses on how what is said or written is to be interpreted.

In a sense, all communicative activities are framings of one kind or another to different degrees. Indeed, all representations can be seen as utilizing frames (though they might more usually be called 'models'). Our use of the notion of frame includes the linguistic dimension (e.g. how key terms such as 'intervention', and 'risk group' are defined), but it is not restricted to this level of analysis. Since our interest is in capturing the multitask activities of Disha, which are not always linguistically articulated, we choose to use the concept of frame to interpret their network of practices (e.g. how the dynamics of interaction between Disha and target groups are accomplished, what overall processes and outcomes are manifest in actionand event-scripts). In short, while Disha frames its activities in terms of development work aimed at improving the conditions of migrants, we argue that its work can be understood as HIV prevention (and eventually that it could be framed as 'quality of life').

At this point it is also worth saying something about the concept of 'risk', as the term figures in much of the argument to follow. It is not our purpose in this article to say anything directly about risk or risk society as theoretical concepts. The use of risk in this article means only the risk of becoming HIV positive. That is not to say that risk as a concept more generally is irrelevant in the HIV context. While Beck's notions of risk and risk society help account for the ways in which government deals with HIV, at an individual level, risk and HIV are very differently related. With respect to the migrant groups that Disha works with, for example, their society is one of scarcity in Beck's terms (1992: 20).

Beck writes, 'In the past, ... hazards could be traced back to an undersupply of hygienic technology' (1992: 21, emphasis in original). However, this is the condition in which migrants are living in the present with respect to development. In many ways, HIV is not a risk at all in the sense that Beck, Giddens and others are concerned with. If we look briefly at the way 
in which Giddens' concepts of external and manufactured risk work, this may become clearer. Giddens' (1999) external risks, typical of traditional societies, have a 'natural' exterior agent. Manufactured risks, on the other hand, are a result of human actions in the world and the consequences of these (global warming, pollution and so on). Effective management of HIV epidemics relies on a sound infrastructure of health and welfare systems. Such systems are typically associated with the industrializing society. These systems are still effectively absent in many parts of the world. It is possible to see HIV from a macro level as something like a manufactured risk. The scale and impact of HIV is closely associated with past (and present) actions in the spheres of public health, education and general public infrastructure. In short, while individually HIV can be understood as an external risk, from a governmental (and global and economic) point of view, HIV is (or is at least involved in other) manufactured risk. ${ }^{6}$ In ideal cases, individuals do have control over their exposure to HIV. Real individuals are not ideal cases, however.

\section{HIVIAIDS strategy of targeted intervention in India}

The system of concepts operative in relation to HIV prevention in India can be collectively identified under the term 'targeted interventions'. This is the mainstay of NACO work in the area of HIV. Material from NACO will thus be examined. This is done in order to discuss and contrast the material from Disha Foundation, which includes interviews, field notes, documentation and funding applications.

Although HIV/AIDS has been reported as having reached epidemic status in India, the official figures show that less than 1 percent $(0.8$ percent, which amounts roughly to 4 million people) are actually affected by the condition. ${ }^{7}$ Although these figures have been challenged for not acknowledging various risk groups because of resource implications and general lack of testing for a variety of reasons, it does provide the basis for the government's unequivocal response of 'targeted intervention', by making prevention the dominant discourse and practice around HIV. Prevention is often the preferred response in economic and moral terms. The National AIDS Control Organization (NACO) is the central authority within the federal Ministry of Health that deals with HIV/AIDS strategy. NACO's primary policy with respect to HIV is that of 'targeted interventions'. This is made clear in NACO's document describing 'Targeted interventions'.

1. One of the ways of controlling the disease from further spread is to

2. carry out direct intervention programmes among these groups through a

3. comprehensive and integrated approach which comprises behaviour

4. change communication, counselling, providing health care support

5. treatment for STDs and creating an enabling environment to facilitate

6. behaviour change. Since most of these groups are extremely 
7. marginalized both socially and economically, it is not possible to access

8. them through conventional Government services. NGOs, Community

9. Based Organizations and other appropriate agencies are able to reach

10. out to these populations more effectively. These groups need

11. information and services in a focused and non judgemental manner. It

12. is, therefore, important to develop a peer based approach which enables

13. and sustains behaviour change. These interventions must be supported

14. by an environment that is conducive to empowering them for behaviour

15. change. $^{8}$ (emphases added)

The policy of targeted interventions brings together a number of concepts. The first is that of the 'target group', referred to as 'these groups' in the second line. This will be further explored in the next section. The second is 'behaviour change communication' (lines 3-4) usually referred to as IEC (Information, Education, Change). Finally, the problems of marginalization and empowerment are raised by NACO, with responsibility for accessing populations and empowering them falling to NGOs and CBOs ('Community Based Organizations'; lines 8-9). Each of these concepts will be examined in turn. First, the concept of target group requires further clarification.

\section{Targeted groups}

The concept of 'risk group', though much criticized, is still used. In the following, we see NACO's attempt to frame 'targeted interventions' with respect to the now more current 'risk behaviour'.

1. All over the world it has been commonly found that particular groups of

2. people are more vulnerable than others to the HIV/AIDS epidemic. These

3. groups because of their behavioural attributes are prone to contract the

4. infection more quickly and spread the disease in a very short period. (NACO Programs Targeted Interventions; emphases added)

Concerns around 'risk groups' and the connection of this to blaming strategies are long-standing (see Watney, 1987; Dodds, 2002). NACO's statement here goes some way in satisfying these concerns by the use of 'vulnerable', something specifically called for by Watney (1987: 127). There are, however, some problematic presuppositions underlying this concern for 'vulnerable' people. The first is their grouping. 'Vulnerable people' here are treated unproblematically as 'groups' (line 3). That people form a 'group' of any kind suggests some kind of similarity among them, exactly that which allows one to 'group' them. NACO's grouping homogenizes at two levels; locally and nationally (or generally). There is a presupposition, for example, that all migrants (a recognized group for targeted interventions) in a particular locale have something that groups them. Further, there is a presupposition that all migrants have something in common relevant to vulnerability. Grouping of people also suggests that it is easy to identify them. We will return to this in terms of 'community'.

The common denominator for these groups, however they are collected, 
is 'behavioural attributes' (line 3). While this may look like 'risk behaviour', it is a curious collocation. While 'attribute' suggests a positive feature (because of its prosody), behavioural attributes that make one vulnerable to HIV are not usually positive (in an evaluative sense). Further, using this noun phrase further erodes agency of individuals (whose individuality has already been erased by their placement in groups). An 'attribute' seems somehow inherent to an individual and thus much harder to change than behaviour.

Thus while this passage does not directly attribute any blame to the vulnerable, because of their 'behavioural attributes' there is an implied responsibility. Further, while it is noted that these groups are 'prone to contract the infection more quickly' what is perhaps more salient is that they are also said to 'spread the disease in a very short period' (lines 3-4). Simply, these vulnerable groups are risk groups renamed. They are vectors of transmission by virtue of their 'behavioural attributes'.

While politically and theoretically the concept of risk groups, especially when they are considered vectors of transmission, is problematic, in the specific context of India (as in other contexts) it is even less appropriate. Married women, for example, are among the most vulnerable of all groups in India (Ananthaswamy, 2003: 42). This is the case for a number of reasons but primarily because of their inability (because of cultural marital norms) to initiate protected sex with their husbands. Certainly they are 'vulnerable' in this sense. But married women are least likely to 'spread the disease in a very short period' for exactly the same reason they are 'prone to contract the infection more quickly'. The common denominator is the expectation of their fidelity and virginity at marriage; thus not a 'behavioural attribute', but a social position. As we will show, the migrants Disha works with are vulnerable in a similar way, that is, because of social positioning. Again, it is migrant women who are often most vulnerable, primarily because of sexual abuse in the workplace or urban environment.

Concerns with social positioning are reflected in the concerns of agencies such as UNAIDS. In their Declaration of Commitment on HIV/AIDS, they recognize that,

... poverty, underdevelopment and illiteracy are among the principal contributing factors to the spread of HIV/AIDS, and noting with grave concern that HIV/AIDS is compounding poverty and is now reversing or impeding development in many countries and should therefore be addressed in an integrated manner. (2001: para. 11)

While the formation of NACO in India recognizes that HIV is a problem with specific characteristics, such specialized agencies are often not properly equipped or structured to offer the integrated solutions that arguably best serve the needs of those vulnerable to HIV. That is not to say that there is an ideal solution for structuring such large (and necessary) institutions. 
In a general way it is easy to talk about integrated solutions and development. As will be discussed presently, however, actually implementing projects in which there is community participation is challenging to say the least. While the discourses of global agencies like UNAIDS appear to mirror the action that Disha and other NGOs take at a local level, the difficulty remains in translating talk of integrated solutions and the like into actual concrete programmes and changes. While this issue will not be pursued here, it should be noted that national and regional infrastructures in the field of HIV often inhibit rather than encourage this translation.

Migrants' 'behavioural attributes'? Migrant workers are specifically seen as a vulnerable group by NACO even though the only thing they may have in common is the fact that they move to seek employment (this being the major cause for internal migration in India). This itself can hardly be understood as a behavioural attribute as framed earlier. Borhade does not work with migrants specifically because of HIV vulnerability. When asked whether HIV was a problem in Nasik, Borhade replied that it is 'very much' a problem. When asked whether some groups are more vulnerable than others, however, she responded: 'No, I must say that everybody is vulnerable to AIDS [...] everybody is at risk' (AB, 11. 595-7). The targeted intervention notion of 'behavioural attributes' suggests that migrants share behaviour patterns that make them vulnerable to HIV; as though migrating itself might lead to HIV.

Typically, migrants are considered at risk from HIV because of movement away from family and thus unsafe sexual activity. The risk of HIV is generally attributed to single male migration and patronage of CSW (commercial sex workers) while away. The tribal villagers that Disha works with tend to migrate as family units thus lowering this particular behaviour. Sexual exploitation of women who work in the construction industry or in agricultural markets, as well as where they stay, however, is high (Disha documentation, see also Allotey, 2003: 7). Significant though this is, it is not a 'behavioural attribute'.

The only 'behavioural attribute' that might be considered relevant to HIV is the use of drugs by Nasik tribal migrants. The work conditions for migrants mean that drug use takes place in the city, even though it is not in the villages. The particular stresses of hard physical work (and the difficulty of getting work) alter practices traditional in village life:

[drug taking is] not the part of the tribal culture [in the villages] but ah see they are doing all the manual and very hard work and in the evening - then they don't have any other leisure or entertainment so they go for that [drug taking]. And they get [drugs] easily on their place [where they stay in the city]. (AB, 1l. 271-3)

This is not intravenous use and the 'risk' is an indirect one inasmuch as drug taking may lead to unsafe sexual activity. Thus the 'risk' behaviour can 
be traced to other causes, here the stress of hard physical work and absence of other entertainment. It is these problems (work and entertainment) that are objects of Disha's interventions. Changing root causes is typical of Disha's ecological intervention. This is not to say that 'symptoms' of root causes are ignored.

Some programmes that Disha runs intervene at points traditionally considered appropriate for such targeted interventions. For example, because sexually transmitted diseases (STDs) make a person more vulnerable to HIV it is imperative that these are treated. Disha ensures that STDs are treated not so much because they contribute to HIV vulnerability, but because they are a problem in themselves. Indeed, women are more likely to be encouraged to access treatment for STDs in India because of the possibility of infertility (Widge, 2002).

Disha provides medical facilities for migrants for the treatment of all medical conditions. Arrangements with pharmaceutical companies have also been made such that medicines are available. The migrants that Disha works with do not otherwise have access to medical facilities. When asked about provision of medical facilities for migrants and particularly why this intervention was considered necessary, Borhade responded,

there is no[t] any medical facility. Because the corporation [local council] have not felt - or any health department have not felt - the need to concentrate on these migrants because it's not - ah oh - it's not felt by anybody that they are the part of Nasik. That is the main problem. (AB, 11. 275-8)

The lack of even running water at the sites where migrants stay in the city means that health problems are common. Apart from nutrition, 'the major [problem] is skin disease. Then - ah - some reproductive health problems like white discharge or some STD problems, then problems related to menses, then problems related to anaemia for women' (AB, 11 . 457-9). Skin diseases are further exacerbated by the manual labour that migrants routinely undertake and are one of the most visible health issues in the field. Reproductive health problems have prompted Disha to begin sexual and reproductive health programmes especially targeted at adolescents and women. However, Disha also stresses the importance of male involvement in these programmes. These medical interventions are necessary because of the social position of migrants, not because of behavioural attributes or even HIV in particular.

It should also be said that figures are not available for HIV levels in migrant populations in Nasik. This should not be surprising. Given that migrants have great difficulty in accessing even basic health care, being tested for HIV is not something they are likely to be equipped to do. Further, even if figures were available, it would be very difficult to generalize about all migrant populations. As we will discuss in the next section, migrants cannot be grouped together. 
Migrants as a group Disha works with a 'migrant community', but not all migrants are the same. While the migrants Disha works with can be identified as economic migrants, they also face problems normally associated with trans-border migration in terms of cultural difference, especially because these migrants are tribal.

The problem of 'identifying' a community mentioned earlier is not a question of simply seeking out groups that happen to be hidden. 'Identification' of a community routinely involves the construction of a community. In Nasik there are at least two kinds of migrant workers:

The first one is the people who are coming from [the] tribal belt around Nasik city and there are ... the [second] migrant people who are from other states [...] so people stay here for a long time - for the whole year. (AB, 1l. 110-14)

The tribals come from around Nasik city. They spend eight to ten months of the year working in the city. Every week (usually on a Wednesday) they return to the village to see relatives. They stay in the villages,

only in the rainy season for two or three or four months are there some jobs in the agriculture. After that they [the tribals near Nasik] don't have water for agriculture and they have to come in [to] Nasik in search of jobs and all that. So it's a forced migration altogether. (AB, 11. 38-41, emphasis in original)

The main problem for these migrants is their lack of basic facilities. The slum settlements of Nasik are too expensive for these village migrants. When in Nasik for employment, families stay on vacant lots (nagas) or on the roadside (footpaths). Disha concentrates on tribal migrants at particular sites in the city and on the tribal villages in the Nasik district from which many migrant workers come. The urban sites where migrants stay, the "holdpoints' where Disha is active, determined which villages have become a focus for work.

For non-migrants, all migrant workers are grouped together. While the work that the migrants provide is essential to the development and growth of Nasik as a commercial centre, the migrants are not considered part of the city. Borhade's view, as mentioned, is that 'it's not felt by anybody that they [migrants] are the part of Nasik. That is the main problem' (AB, 11 . 277-8). This suggests that migrants are not a popular group in terms of any kind of social intervention and explains why the council does not provide medical services for example (though this is a question of access and provision). This is also supported by Disha being the only NGO in Nasik to be working with tribal migrants. ${ }^{9}$

Thus while on paper Disha can claim to have 'accessed' a community, it was not waiting ready-formed for intervention as NACO materials suggest with their use of 'groups'. The first stage of Disha's work was exactly to identify and construct a community. Links with individuals were formed and these grew through a chain of personal contacts until villages got to 
know Disha's staff. This took about a year and involved visiting the villages and nagas, talking to people at length and helping them solve immediate problems (AB, 1l. 731-5). This 'basic work' continues every time Disha is in the field. Such rapport is fundamental to ecological interventions and indeed to HIV interventions. An environment for intervention has to be established. Further, only through investing in such relationships is it possible to come to understand a situation well enough to actually conduct an ecological intervention.

In targeted interventions, the problems that an NGO routinely works with are related to sexual health, information about prophylactics and access to medical treatment. It is clear that it can be incredibly difficult to raise such issues before an NGO has rapport with a community. This is also recognized by the NACO imperative that NGOS already have 'credibility' and existing relationships with the communities that they intend to work with. This is presupposed such that funding for community building is not routinely available (at least not under NACO funding).

\section{Changing attributes and planning behaviour change}

The main method of behaviour change is based on the IEC model (as mentioned earlier in targeted interventions): Information, Education, Change. This model is routinely invoked in NACO documents in exactly these terms. The theory behind IEC is that, given the appropriate knowledge, people will alter their (risk) behaviour. However, information is never just information: "One of the many shortcomings of the more basic IEC approaches is the fact that "quality messages" or "information" are often treated as somehow objectively independent from the messy reality of local contexts' (Edström et al., 2002: 114, emphasis added).

If an NGO takes this 'messy reality' into account and adapts its messages, it exposes itself to adverse consequences. 'NGO teachings are actually policed. Their upstream accountability to the international donors who sponsor their work requires that they be factually accurate by the measures of accuracy set elsewhere' (Leigh Pigg, 2001: 510). Disha does provide such 'factually accurate' information when running awareness programmes on sexual and reproductive health. ${ }^{10}$ These programmes began two years after starting to work with tribal migrants. Finding out answers to questions about how communities think and speak (the latter if at all) about such issues requires a foundation of trust and close rapport. ${ }^{11}$

However, sometimes the best way to bring HIV knowledge into a community is not to talk about HIV. Butcher and Welbourn write,

HIV is normally not the issue at the front of the minds of the people with whom we may be trying to work. This is true even of people in countries with a high prevalence of HIV ... It follows from this that, if international funders rush in to promote their concerns about HIV ... there is a great chance of doing more harm than good. (2001, emphasis in original) 
If HIV is not perceived as a priority, attempting to run programmes on it may well jeopardize relations with the community. This in turn makes it impossible to do any kind or work, HIV or otherwise.

These differences between communities are sometimes addressed in terms of 'audience segmentation'. Yun et al. comment that 'only a strategy firmly rooted in a subculture (be it defined in economic, psychographic or political terms) can result in behavior change for members of that subculture' (2001: 74). However, this still relies on a basic IEC model and as such can only negotiate differences superficially. Sometimes the very profile of the audience (in economic or political terms) needs to be altered before a message will have meaning.

NACO have foregrounded the importance of protecting the marginalized and facilitating empowerment, and part of any successful HIV intervention must involve engaging with these issues. Barnett and Whiteside comment,

[t] he problem is that even if people have the knowledge, they might not have the incentive or the power to change their behaviour. If prevention is to move beyond knowledge to action, we must look at the socio-economic causes of the epidemic and intervene there too. (2002: 42)

This makes clear the connection between behaviour change, change of social position and empowerment.

An ecological intervention approach would dictate that root causes of problems should be solved. Taking best advantage of the economics of prevention, providing clean water, for example, should be a cheaper alternative than curing the resulting ills. The attempt to organize migrant labour in the city is another of Disha's initiatives and seeks to reduce all forms of exploitation in the workplace. Programmes such as this are designed to change the conditions of urban migration. It is not so much an attempt to change migrants' behavioural attributes but to encourage change in others' behaviour towards them and, more importantly, to change the migrants' environment such that 'risks' are not an issue. To do this effectively requires a sound understanding of migrants' lives, the hazards they face and, more importantly, where these problems originate. Further, an ecological perspective takes heed of resources within the community.

\section{One more step: marginalization and empowerment}

NACO stresses the importance and difficulty of working with groups that are marginalized and disempowered. NACO also recognizes that NGOs are best placed to do this work. From an ecological intervention point of view, NGOs should not only work with those who are marginalized but attempt to empower them and bring them centre stage.

As seen earlier, migrants do not necessarily have 'behavioural attributes' that would put them at risk from HIV. Certainly stopping exploitation in the workplace and some information about sexual health are needed. The 
more general and fundamental problem of social exclusion remains. In identifying root causes and intervening at these points, the ecological model has empowerment as telos. To solve workplace exploitation, for example, requires empowerment of migrants with respect to their employers. Empowerment is not localized to particular topic areas. It is difficult to imagine that someone could be empowered with respect to their sexual activities if they were not, for example, economically empowered (see Poppen and Reisen, 1997: 380).

\section{The roots and branches of migration: an ecological perspective}

Characteristic of Disha's intervention is that it is dialogic. Borhade states quite clearly, 'it's not my view; it's what the communities need' (1l. 8-9); more importantly, what the communities have asked for. Work is conducted in consultation with the community from start to finish. This echoes in practice what is well documented in theory (see Morris, 2003: 239). For example, when a school was requested in the village, Disha helped source materials for the school and a salary (from the government) for a teacher. However, the teacher is from the village and the work required on a preexisting building in the village was undertaken by the villagers. As a result, children willingly attend the school with the encouragement of their parents. Disha simply provides some missing resources and guidance about how to continue, including liaising with local schools in Nasik to allow students from the villages to take accredited exams there (something not possible in the village).

A number of other projects were started at the request of the migrants; extended day school for children in the city (as both parents usually work), and assisting with plans for agricultural production and sale. In terms of resources required to get these projects running, it is Disha's view that as much as possible these should come from the community.

So ... having discussions with the villagers and initiative from [the] villagers we - ah - decided that strategies should be applied to get these troubles tackled and we started to - ah to - address some local resources for that. We wanted - I mean it's the policy of Disha that we don't want to - ah - get something from outside [of] that village regarding their development. We want to get their development with their own available resources. And there are many available resources there. Many. Plenty. (AB, 11. 480-6)

Borhade sees this as essential to development generally. 'It's very ... important to [get these people to] realise ... that the development is in your hands, on you. And there is nobody [who] will come and get your development [for you]' (11. 530-1). It also means that interventions are sustainable. Interestingly, the idea of using 'available resources', is specifically welcomed by UNAIDS (2001: para. 27). 
Disha, in close consultation with the villagers, decided that migration itself was the problem. Thus while Disha's interventions in the city seek to alleviate the problems of migrants who have migrated, Disha is seeking to tackle the problem at its core. Disha's interventions extend to the village with the aim of halting migration altogether. Here, the main problem is lack of water for agriculture. Borhade characterizes their migration as 'forced' because of this. Put simply, the migrants do not want to migrate. But because conditions in the village are so difficult, they feel they have no choice.

The lack of water is so acute that while the villagers have been provided with sanitation facilities by the tribal development commission, these cannot be used throughout the year. However,

there is a very big dam some 5-10 kilometres long, 10-15 kilometres distance from that village. And there is a canal going from that village, from 5 villages. But there is many leakages in that canal and that is why the water is not coming so we are trying to get that leakages fixed so the problem of water can get sorted. (AB, 11. 487-91)

The second problem has to do with marketing agricultural products. While there is great demand for the produce, the villagers do not have the skills to procure the best price for it. This has also been taken up by Disha through organizing trading networks and consortiums in order to get proper market value for the villagers' products.

As Borhade notes, development is in the hands of the community. Disha is prepared to go beyond the traditional territories inhabited by other NGOs, literally (to the outlying villages) and in terms of ecological interventions. While 'perfect' solutions may not be possible, workable solutions are. Such solutions should be based upon resources available and challenges at hand. The ecological approach is one that is participative, dialogic and dynamic.

\section{Empowerment: the origin of change}

Targeted interventions seek to provide protection from the threat of HIV by arming people with knowledge about transmission. In this sense, all NACO interventions seek to prevent HIV. Underpinning these interventions/prevention efforts is the belief that behaviour change is essential to halting the spread of HIV. This assumes that behavioural attributes are always problematic and always possible to change. While NACO mentions empowerment in terms of the resources required to change behaviour, social positioning is not explicitly connected to HIV risk. NACO appears only to consider such marginalization in the context of accessing groups.

Disha's understanding of intervention is based on deep analysis of what is required to make the social environment conducive to change around HIV. As is clear, in various places HIV is not simply a health problem. But the changes that are required to create an environment where HIV-specific interventions will even be seen as salient are fundamental. Yun et al. 
comment that, 'While a virus causes AIDS, fundamental driving forces behind the speed at which spreads and factors that influence prevention are poverty (economic), gender, religious, spiritual and ethnic norms (cultural), and national policy (political)' (2001: 73). Basic health problems, access to shelter and water, sustainable agricultural industry in the villages, decent working conditions, are all more prominent for migrant workers than HIV. Further, in terms of root causes and tracking problem development, these lacks are what put migrant workers at risk with respect to HIV. If there is risk from HIV, it is traceable back to social positioning rather than behavioural attributes. Dodds comments, 'Effective public health efforts will need to go beyond risk reduction, and begin to tackle the heart of economic and social inequality' (2002: 167).

\section{Conclusion: reframing HIV/AIDS as a quality of life issue}

We noted earlier that HIV is not raised by Disha as a specific issue. Rather, Disha's interventions focus on education, employment, organization of labour and marketable materials and the provision of natural resources. Put simply, Disha can be understood as reframing development (and HIV) as a quality of life issue. Indeed, Disha was founded to 'minimize the migration rate of tribals from Nasik region towards Nasik city facilitating them in improving the quality of their lives and providing them with opportunities to become more productive assets of society' (Disha profile document; emphasis added).

While we have discussed Disha's work in terms of an ecological model of intervention, in purely strategic terms it may be more appropriate to frame such work in terms of 'quality of life'. Significantly, 'quality of life' (admittedly a problematic concept) is one that has currency in the global health arena. To describe interventions in this way can be seen as framing upward, aligning with global health policy. It is essential that the ecological model is retained, however, in order to frame downward effectively to communities and to analyse environments and their problems in terms of root causes.

Disha's agenda mirrors the World Health Organization's definition of 'quality of life':

Quality of life is defined as individual's perceptions of their position in life in the context of the culture and value system where they live, and in relation to their goals, expectations, standards and concerns. It is a broad ranging concept, incorporating in a complex way a person's physical health, psychological state, level of independence, social relationships, personal beliefs and relationship to salient features of the environment. (WHOQOL Group, 1994)

The second part of this definition is particularly salient. Base-level needs such as health, work, shelter and water are presumed in this definition. Disha is working to bring migrant workers to a place where thinking about 
more abstract 'goals, expectations, standards and concerns' is even possible. The threshold that this definition of 'quality of life' assumes, is that which Disha is aiming for. Further, given the emphasis in development circles on rights-based initiatives, quality of life is a useful theoretical and lobbying tool.

This implicit reframing of HIV as fundamentally a quality-of-life issue explains why HIV is not foregrounded in interviews, documentation or interventions. While development is the primary orientation of HIV programmes in India, HIV is usually foregrounded and targeted in order to align with national bodies and politics (and indeed with the philosophy of targeted interventions). The backgrounding of HIV in such an extreme way, along with the salient reframing of community problems, is not simply rhetoric. It is an embodiment of best practice.

Framing 'problems' and 'solutions' is not usually something that NGOs are allowed to do. 'Large or powerful organizations and not the recipients of innovations usually have the opportunity to frame social "problems" in campaigns' (Melkote and Steeves, 2001: 242). This is one way of explaining why Disha does not explicitly challenge the concepts ratified by NACO. In fact they do not engage with NACO at all. Rather, Disha's ecological approach can be understood as unpacking, and extends these concepts in order to engage with deep structures. Salmon writes,

Particularly in the case of public information campaigns, for which the government is the primary source of funding, it is unusual for funds to be disbursed to change the system rather than changing individuals responding to the system. It is because of this that most campaigns can be viewed as efforts to induce evolutionary rather than revolutionary changes. (1989: 27 in Melkote and Steeves, 2001: 242)

If migrants are actually to be relieved of their risk status in respect of HIV, there have to be revolutionary changes. They are changes that deal not only with health but also with economic, social and environmental change. The changes that need to be made may be as simple as fixing a canal that leads from a dam. But the results of this may well be revolutionary, halting migration altogether. Most importantly, they are changes that can only be identified as important if HIV risk (if this is to remain on the agenda) is taken as a starting point for intervention and development rather than an end in itself.

In terms of cause and effect, Disha's activities are such that they should prevent HIV even becoming an issue. This in itself is problematic in terms of justification of programmes and monitoring of success in the specific arena of HIV.

If you plan for impact [of HIV] and avert it, then how do you justify what you did, to show that your planning and use of resources was necessary? To plan effectively for impact should turn out to be a self-defeating prophecy: what is prophesied does not happen. The paradox is further deepened when it becomes 
apparent that to educate people about potential impacts on the epidemic may be part of prevention. (Barnett and Whiteside, 2002: 321)

That the kind of work that Disha does is probably not institutionally recognized as HIV work even though it goes to the root of the problem and seeks fundamental social change. There are two difficulties. Because such fundamentally ecological work is not recognized as targeted HIV work (as not framed in these terms), it cannot avail itself of HIV-dedicated funds. Second, and consequentially, the deployment of NGOs in the field is not being fully capitalized upon. Should NACO shift its discourses and requirements, for example, to one of quality of life primarily with HIV as a secondary emphasis, the very attempt of NGOs to frame their programmes in such terms would bear testament to the research, thought and experience behind them. Such a frame would allow NGOs to put forth in an original and recognizable way their own particular expertise; something that is not always possible under present conditions.

The fact that Disha is not identified as an HIV NGO immediately raises questions about whether it is appropriate to situate their work with respect to HIV discourse. We contend that despite the lack of identification, the work that Disha performs prevents HIV by intervening in a particular community in an ecological way. As has been discussed, 'community', 'prevention' and 'intervention' are neither given nor straightforward. However, if programmes are to deal successfully with HIV, they should perhaps look more like Disha's interventions than the programmes usually encouraged by NACO. ${ }^{12}$

If NGOs are able to continue to do that which they are best at, flexible protocols with respect to framing and delivering interventions will need to be ecologically developed and institutionalized. Disha intervenes and arguably prevents HIV but not using the government model of targeted interventions. Behavioural attributes are understood not so much as individual (or even group) behaviours, but as the environment in which people find themselves that conditions or determines behaviour. As Borhade notes, the migration from village to city is 'forced altogether' (11. 40-1) because of conditions in the villages. An ecological model seeks to change these conditions, improve quality of life and, as a consequence, prevent HIV.

\section{Notes}

1. The BBC World Service Trust, for example, has been running HIV/AIDS awareness campaigns in India.

2. Thus the development of an effective microbicide is of great importance.

3. Transcription is broad with pauses marked (.) Dashes have been added for ease of reading.

4. Though this was a training for trainers, part of this involves potential trainers moving through the Stepping Stones programme as though members of a common community. The package challenges many aspects of the paradigms in which people think and live. 
5. ActionAid UK and Bangalore generously facilitated participation in this workshop, a training of trainers. The training was also supported by ICHAPS (India-Canada Collaborative HIV/AIDS Project) in Bangalore. Stepping Stones is a community development package developed under the Strategies for Hope, sponsored by ActionAid. The programme was developed initially in Uganda by Welbourn and has been adapted to local conditions and used in a variety of contexts (for information see http://www.actionaid.org/stratshope/ tp.html).

6. See Lupton (1993) for discussion of intersection of the individual and institutional around risk.

7. Though recent news puts it at just over 5 million. See Reuters, 13 August 2004.

8. For all NACO documentation unless otherwise indicated, see www.naco.nic.in

9. Though migrants are identified as a vulnerable group by NACO, there are only five programmes in the whole of Maharashtra working with NACO on this group.

10. Borhade is the author of a book for doctors on HIV in Marathi.

11. Knowledge about 'basic' reproductive health is closely related to this. Finding a framework of the body in which explanations about transmission, prevention and illness progression make sense is a project in itself (see Cornwall (2002)).

12. We are not suggesting that there are not innovative and ecological interventions undertaken elsewhere, by other organizations. Rather, the funding structures currently in place do not necessarily encourage them.

\section{References}

Allotey, P. (2003). Is health a fundamental right for migrants? Development, 46(3), 7-9.

Altman, D. (1997). The emergence of a non-government response to AIDS. Mots Pluriels, 1(3), http://www.arts.uwa.edu.au/MotsPluriels/MP397da.html

Altman, D. (2001). Global sex. Chicago, IL: University of Chicago Press. Ananthaswamy, A. (2003). Culture shock. New Scientist, 25 January, 42-5.

Barnett, T. and Whiteside, A. (2002). AIDS in the twenty-first century: Disease and globalization. Basingstoke: Palgrave.

Beck, U. (1992). Risk society: Towards a new modernity. Trans. M. Ritter. London: Sage Publications.

Butcher, K. and Welbourn, A. (2001). Danger and opportunity: Responding to HIV with vision. Gender and Development, 9(2), 51-61. Accessed at http://www.actionaid.org/stratshope/sstantqu.html

Cornwall, A. (2002). Body mapping: Bridging the gap between biomedical messages, popular knowledge and lived experience. In A. Cornwall and A. Welbourn (Eds.), Realizing rights: Transforming approaches to sexual and reproductive well-being, pp. 219-34. London: Zed.

Dodds, C. (2002). Messages of responsibility: HIV/AIDS prevention materials in England. health: An Interdisciplinary Journal for the Social Study of Health, Illness and Medicine, 6(2), 139-71.

Edström, J. with Cristobal, A., Sellers, T. and de Soyza, C. (2002). Ain't misbehavin': Beyond awareness and individual behaviour change. In A. Cornwall and A. Welbourn (Eds.), Realizing rights: Transforming approaches to sexual and reproductive well-being, pp. 113-27. London: Zed. 
Edwards, M. and Hulme, D., Eds. (1995). Non-governmental organisations performance and accountability: Beyond the magic bullet. London: Earthscan Publications.

Fairclough, N. (2003). Analysing discourse: Textual analysis for social research. London: Routledge.

Fillmore, C.J. (1982). Frame semantics. In The Linguistic Society of Korea (Ed.), Linguistics in the morning calm, pp. 111-37. Seoul: Hanshin Publishing Company.

Giddens, A. (1999). Runaway world: How globalisation is reshaping our lives. London: Profile Books.

Goffman, E. (1974). Frame analysis: An essay on the organisation of experience. New York: Harper \& Row.

Jenkins, C. (1993). Culture and sexuality: Papua New Guinea and the rest of the world. Venerology, 6(3), 55.

Karnik, N.S. (2001). Locating HIV/AIDS and India: Cautionary notes on the globalization of categories. Science, Technology, and Human Values, 26(3), 322-48.

Leigh Pigg, S. (2001). Language of sex and AIDS in Nepal: Notes on the social production of commensurability. Cultural Anthropology, 16(4), 481-541.

Lupton, D. (1993). Risk as moral danger: The social and political functions of risk discourse in public health. International Journal of Health Services, 23(3), 424-35.

Melkote, S.R. and Steeves, H.L. (2001). Communication for development in the third world: Theory and practice for empowerment, 2nd edn. London: Sage Publications.

Morris, N. (2003). A comparative analysis of the diffusion and participatory models in development communication. Communication Theory, 13(2), 225-48.

Pais, P. (1996). HIV and India: Looking into the abyss. Tropical Medicine and International Health, 1(3), 295-314.

Poppen, P.J. and Reisen, C.A. (1997). Perception of risk and sexual self-protective behavior: A methodological critique. AIDS Education and Prevention, 9(4), 373-90.

Potterat, J. (1993). Prostitution: A global public health issue. Venerology, 6(3), 85.

Sen, A. (2000). Development as freedom. New Delhi: Oxford University Press.

UNAIDS. (2001). Declaration of commitment on HIV/AIDS. Geneva: UNAIDS.

Vasudev, S. (2002). The mess of AIDS. India Today, 9 December: 50-60.

Watney, S. (1987). The subject of AIDS. Copyright, Fall 1, 125-32.

Welbourn, A. (1995). Stepping stones. London: ActionAid.

Welbourn, A. (1999). Gender, sex and HIV: How to address issues that no-one wants to hear about. Tant qu'on a la Santé. Berne, Switzerland: IUED. Accessed at http://www.actionaid.org/stratshope/sstantqu.html

WHOQOL Group. (1994). Quality of life assessment. Geneva: WHO.

Widge, A. (2002). Sociocultural attitudes towards infertility and assisted reproduction in India. In E. Vayena, P.J. Rowe and P.D. Griffin (Eds.), Current practices and controversies in assisted reproduction, pp. 60-74. Geneva: UNAIDS.

Yun, H., Govender, K. and Mody, B. (2001). Factoring poverty and culture into HIV/AIDS campaigns: Empirical support for audience segmentation. Gazette, 63(1), 73-95. 
health: 9(3)

\section{Author biographies}

ANNABELLE MOONEY is a Research Associate on a Leverhulme-funded project at Cardiff University in the Centre for Language and Communication Research.

SRIKANT SARANGi is Professor and Director of the Health Communication Research Centre at Cardiff University. His research interests are in discourse analysis and applied linguistics; language and identity in public life and institutional/professional discourse (e.g. health, social welfare, bureaucracy, education etc.); quality of life and risk communication in genetic counselling, HIV/AIDS, oncology, cancer genetics, palliative medicine, telemedicine, general practice; intercultural pragmatics; ethnicity and discrimination in multicultural societies. His recent book-length publications include Language, Bureaucracy and Social Control (1996, with S. Slembrouck); Talk, Work and Institutional Order: Discourse in Medical, Mediation and Management Settings (1999, with C. Roberts); Discourse and Social Life (2000, with M. Coulthard); and Sociolinguistics and Social Theory (2001, with N. Coupland and C.N. Candlin). $\mathrm{He}$ is currently editor of TEXT: An Interdisciplinary Journal for the Study of Discourse, and founding editor of Communication \& Medicine and (with C.N. Candlin) of the Journal of Applied Linguistics. He is also general editor (with C.N. Candlin) of three book series: Advances in Applied Linguistics, Studies in Applied Linguistics and Communication in Public Life. 